\title{
Invited review: reproductive physiology in commercial and premium pig breeds - history of 30-year-long cooperation
}

\author{
József Rátky ${ }^{1}$, István Egerszegi ${ }^{2}$, Tamás Páble ${ }^{3}$, Eszter Balogh ${ }^{4}$, Noboru Manabe ${ }^{5}$, \\ Soukanh Keonouchan ${ }^{6}$, and Klaus-Peter Brüssow ${ }^{7}$ \\ ${ }^{1}$ Faculty of Agriculture, Food Science and Environmental Management, University of Debrecen, Debrecen, \\ Hungary \\ ${ }^{2}$ Faculty of Agricultural and Environmental Sciences, Szent István University, Gödöllő, Hungary \\ ${ }^{3}$ Vitafort AgroAsia Co, Dabas, Hungary \\ ${ }^{4}$ Research Institute for Animal Breeding, Nutrition and Food Science, National Agricultural Research and \\ Innovation Center, Herceghalom, Hungary \\ ${ }^{5}$ Faculty of Agriculture, Osaka University, Osaka, Japan \\ ${ }^{6}$ National Agricultural and Forestry Research Institute, Vientiane, Laos \\ ${ }^{7}$ Leibniz Institute for Farm Animal Biology, Dummerstorf, Germany
}

Correspondence to: József Rátky (jozsefratky@gmail.com)

Received: 20 March 2017 - Revised: 21 June 2017 - Accepted: 5 July 2017 - Published: 4 August 2017

\begin{abstract}
Cooperation of the Hungarian Research Institute for Animal Breeding and Nutrition (ATK) with the German Leibniz Institute for Farm Animal Biology (FBN) goes back many decades. In 1988 the two departments of reproductive biology began a joint project concerning on ovulation investigation in Landrace pigs. This joint project laid the foundation for further joint projects and has existed for almost 30 years. Over the years, the main focus has always been on the events of the female reproductive tract in pigs, i.e., follicular growth, ovulation, transport of gametes in the oviduct, fertilization and early embryonic development. Nearly all studies were done under in vivo circumstances and using different clinical and endocrinological methods, enabling us to obtain more profound knowledge of the dynamics of reproductive processes. Even results considered to be basic scientific achievements were available for utilization in the daily practice of porcine reproductive management. Since the end of the 1990s, the common projects have been gradually shifted to the physiology of the Hungarian indigenous pig breed Mangalica. Research partners were convinced that modern utilization of indigenous pig breeds would open new doors for premium pork production. In addition to the Mangalica breed, this principal was broadened to non-European fatty-type native pig breeds as well and resulted in long-term, intercontinental scientific cooperation.
\end{abstract}

\section{Introduction}

Apart from any political system, pig breeding and relevant research has always played an important role in the last 100 years in both Hungary and Germany. Consequently, there has always been a highly developed agriculture sector using the results of innovation. Conversely, general history of the two countries has also grown together during recent centuries. Thus, it was natural that scientific cooperation also existed and many times it was prosperous. In the field of animal science and pig research, cooperation began in the 1960s when the East German Research Center for Animal Production Dummerstorf and the Hungarian Research Institute of Animal Breeding and Nutrition Herceghalom had an official partnership with regular consultation and short-term visits. On the basis of the partnership and encouraged by their superiors in 1988, two young researchers carried out a joint experiment in Dummerstorf to investigate porcine ovulation 
dynamics. The week-long experiment was not only successful in terms of scientific achievements but was also promising for the future and thus it was decided to move forward together.

The team was aiming to complete the knowledge of the ovulation process and later ovarian morphological and physiological changes during the estrous cycle. Later, the necessary preconditions for fertilization in the fallopian tube and afterwards the early embryonic development and uterine capacity were observed. From the second half of the 1990s the partners began to work with the Hungarian indigenous pig breed, the Mangalica. The Mangalica was, at this time, an endangered breed and with 154 breeding sows in 1994, had nearly disappeared. From that time, the Mangalica breed played an important role in research programs and the results contributed to the renaissance of this typical Hungarian native pig breed, producing premium-quality pork. The research team could demonstrate some significant differences between the reproductive physiology of Landrace and Mangalica pigs. For the propagation of the dangerously reduced Mangalica pig population, they applied new embryo transfer methods, i.e., developed and applied endoscopic embryo recovery and assisted the establishment of effective artificial insemination (AI) at production farms in Hungary. Interestingly, the research in native pigs attracted European and non-European scientists and resulted in further joint projects for other indigenous pig breeds (Rátky et al., 2013). A valuable by-product was the series of Fatty Pig Conferences held in Herceghalom, Hungary, in 2011, 2013 and 2015, which gave a floor for dedicated native pig researchers from $\mathrm{Eu}-$ rope, Africa, Asia and North America.

Nearly all studies were talking about in vivo environments, in which the aim was to collect data and improve our knowledge of natural procedures capable of transforming farmers' daily practice and developing their results in pig and pork production.

\section{Research topics and results}

In programs aimed at modern pigs, crossbred Landrace $x$ Large White gilts (either prepuberal or cycling) were usually used in the experimental plan. In the Mangalica breed, research gilts played the main role and modern pigs served as control groups. It is nearly impossible to calculate the number of experimental animals studied over the 30 years; however, it is estimated that over 2000 and altogether more than 6000 different surgical and minimally invasive interventions were performed. It is necessary to mention that during the 3 decades of research the observation of morphological events was mostly completed by endocrinological measurements. Prior to many experiments, catheters were inserted either in the vena saphena or vena jugularis and sometimes blood was collected from the vena ovarica (Egerszegi et al., 2003b; Brüssow et al., 2008). According to the experimen- tal schedule, blood samples were regularly collected through catheters and analyzed for reproductive hormones. In this way morphological features and changing hormonal status were both taken into consideration.

\subsection{Determination of the ovulation period using a minimally invasive technique}

In the first stage of the cooperation, the ovulation process was investigated in estrus-synchronized and spontaneously cycling gilts, and the duration of ovulation was determined. A minimally invasive abdominal surgical technique, i.e., laparoscopy, was mainly used to avoid disturbance of physiological events (Brüssow and Rátky, 1994; Rátky et al., 1995). Prior to our cooperation, not many researchers used abdominal endoscopy in female swine and repeated procedures in short time intervals were nearly never performed. We used the advantages of laparoscopy to follow the changing morphology of reproductive organs several times on the same animal in a short time interval. Ovarian development was followed using repeated laparoscopic visualization in gilts during the estrous cycle, i.e., from one ovulation until the next, and continuously in gilts of different age and sows (Rátky et al., 1995; Brüssow et al., 2002; Rátky et al., 2005). The process of ovulation was also determined after ovulation induction with different GnRH formulations (Brüssow et al., 1994, 2007). Since the ovulation period can extend up to $8-10 \mathrm{~h}$, we could conclude that mating or AI should be performed twice in farm practice. Ovulation features as well as oocytes and early embryos that were recovered during different experiments were documented in photographs.

\subsection{Novel applications of endoscopy in pigs}

In the course of our cooperation, we developed new applications of endoscopy in swine. Since previously oocytes could only be recovered from porcine follicles surgically or after slaughter, we developed a minimally invasive method of oocyte recovery that can be frequently applied (Brüssow and Rátky, 1996; Brüssow et al., 1997). In vivo matured oocytes were repeatedly collected using laparoscopic ovum pickup to evaluate ovum quality (Torner et al., 1998, 2004). The results contributed to the determination of the oocyte structure and fertilization capacity of in vivo matured eggs, e.g., compared to in vitro maturation and subsequent fertilization (Rátky et al., 2003).

Furthermore, laparoscopic handlings were also used for sampling of oviductal fluid and transferring of oocytes and sperm into the reproductive tract to highlight the influence of follicular components on sperm migration and fertilization (Brüssow et al., 1999a, b, 2006). Laparoscopic intrauterine or intraperitoneal insemination was also applied in gilts to study the route of sperm migration (Brüssow et al., 2011). Single intrauterine insemination close to ovulation was also performed to obtain low-diversity embryos (Brüssow et al., 
2013). These results contributed to the determination of the perfect timing of AI too.

One main result of this beneficial collaboration was the development of minimally surgical recovery of porcine embryos (Rátky and Brüssow, 1995; Rátky et al., 2001). In pigs, embryos are usually only recovered surgically, which minimizes the repeated use of donors. Our method allows repeated embryo recovery and was especially developed for embryo transfer in Mangalica pigs.

\subsection{Research in Mangalica pig}

The fatty-type breed Mangalica was the most important breed in Hungary, with 30000 breeding sows in 1943 and about 18000 in 1955 (Brüssow et al., 2005). However, due to the breeding of modern commercial pig breeds and changing consumer habits, the Mangalica breed had nearly disappeared and only between 154 and 346 registered sows in 1994-1996 remained (Egerszegi et al., 2003a). In 1996 a Hungarian state program was established to propagate the Mangalica breed. Today, about 8000 Mangalica breeding sows are kept again. Our Hungarian-German research cooperation was a part of this main project. In addition to the applied physiological research projects, we wanted to contribute directly to the propagation of the Mangalica population. Since modern sows can give birth to many more piglets than Mangalica sows, interbreed embryo transfer programs were scheduled. Superovulated Mangalica females served as donors and commercial sows as recipients (Rátky and Brüssow, 1995; Rátky et al., 2001). In one litter of transferred embryos we could obtain 12 to 13 Mangalica piglets from the modern recipients instead of 6 to 7 piglets born naturally in Mangalica litters. Moreover, using laparoscopic embryo collection, some Mangalica pig donors could be involved in the program two or three times. The impact of embryo transfer in Mangalica breeding quickly disappeared when the population grew and in a couple of years the Mangalica breed was declared no longer endangered.

Despite the relatively long history of the Mangalica breed, only very few physiological and reproductive data were available. One goal of our collaboration was to determine actual morphometric data of the genital tract, oocyte and embryo development, and early pregnancy. Furthermore, endocrine studies should highlight possible causes of the low fecundity in Mangalica pigs.

We could demonstrate that Mangalica gilts differ considerably from Landrace gilts. In addition to diminished follicle and intrafollicular oocyte development (Egerszegi et al., 2001), they have restricted uterine growth (Brüssow et al., 2004). Furthermore, there are crucial differences in the secretion of reproductive hormones. The intrafollicular progesterone $(\mathrm{P} 4)$ concentration is 5 times higher compared to Landrace pigs (Egerszegi et al., 2007), and despite the lower number of corpora lutea, the concentration of $\mathrm{P} 4$ in the circulation near the ovary is 4 times higher. Additionally, the pul- satile secretion of luteinizing hormone is suppressed, which influences follicle recruitment and development and the level of leptin is increased fourfold (Brüssow et al., 2008). Altogether, altered follicle and oocyte development, restricted uterine growth, and different reproductive hormone levels are involved in mechanisms influencing the fecundity in this breed.

The Hungarian Mangalica pig breed has attracted more commercial and scientific interest since the mid-1990s. During this period of more than 20 years, we could figure out the physiological differences between the indigenous and modern pig breeds. Based on our research results, we were able to support the reproductive management and upgrade of the AI protocol in Mangalica gilts and to understand the diminished reproductive capacity compared to that of commercial breeds.

Since the beginning of the 2000s, our Mangalica breed reproductive research programs have begun to study male pigs as well. Apart from specific andrological and spermatological investigation, extender optimization, and deep freezing development, we introduced new AI methods in Mangalica reproductive management and in vivo gene preservation with optional parentage testing (Egerszegi et al., 2009a, b, 2010; Sarlós et al., 2011; Zsolnai et al., 2013).

\section{Summary and outlook}

During our 30-year-long cooperation, we were able to collect physiological and reproductive data, especially with respect to fatty pigs. We emphasize the methodological development aiming to upgrade clinical experiments, i.e., laparoscopic observation, laparoscopic ovum collection, endoscopic oviduct surgery and embryo collection. The clinical experiments were nearly always combined with endocrinological analysis for obtaining multi-approach data and scientific evidence.

Altogether, we can declare that the 3-decade-long research cooperation produced many basic scientific results for the international pig research community and numerous applied achievements for the improvement of practical pig farming in both the commercial and premium pig sectors. Joint projects of the FBN and ATK drew together other teams from Europe, such as Spain, the Netherlands, Poland, Austria and United Kingdom, and outside of Europe Japan and then Thailand, Laos, and South Africa. We have found enthusiastic partners who are interested in fatty pigs - breeds that can hopefully find a niche in the market as with Mangalica and Spanish Iberian pigs. Younger colleagues joined us and we strongly wish that they will step forward in the ongoing cooperation between countries and institutes.

Data availability. No new data sets were used in this article. 
Competing interests. The authors declare that they have no conflict of interest.

Edited by: Manfred Mielenz

Reviewed by: two anonymous referees

\section{References}

Brüssow, K.-P. and Rátky, J.: Repeated follicular puncture and oocyte aspiration in swine, Reprod. Dom. Anim., 29, 494-502, 1994.

Brüssow, K.-P. and Rátky, J.: Endoscopic collection of porcine embryos, Reprod. Dom. Anim., 31, 711-715, 1996.

Brüssow, K.-P., Kanitz, E., and Rátky, J.: The dynamic of plasma luteinizing hormone surge and its relationship to the time of ovulation in gilts following exogenous GnRH, Arch. Tierz., 37, 5563, 1994.

Brüssow, K.-P., Torner, H., Rátky, J., Hunter, M. G., and Nürnberg, G.: Ovum pick up in swine: The influence of aspiration vacuum on the morphology of cumulus oocyte complexes and on oocyte recovery from preovulatory follicles, Acta Vet. Hung., 45, 189196, 1997.

Brüssow, K.-P., Rátky, J., Torner, H., Sarlós, P., and Solti, L.: Contribution of follicular fluid in the process of fertilization in vivo, Reprod. Dom. Anim., 34, 139-145, 1999a.

Brüssow, K.-P., Rátky, J., Schneider, F., Torner, H., Kanitz, W., and Solti, L.: Effects of follicular fluid on the transport of porcine oocytes into the oviduct at ovulation, Reprod. Dom. Anim., 34, 423-429, 1999b.

Brüssow, K.-P., Rátky, J., Torner, H., Egerszegi, I., Schneider, F., Solti, L., and Tuchscherer, A.: Follicular and oocyte development in gilts at different age, Acta Vet. Hung., 50, 101-110, 2002.

Brüssow, K.-P., Egerszegi, I., Rátky, J., Soós, F., Garcia Casado, P., Tuchscherer, A., and Toth, P.: Organometric data of the reproductive tract in cycling and early pregnant Hungarian Mangalica pigs, Arch. Tierz., 47, 585-594, 2004.

Brüssow, K.-P., Egerszegi, I., Rátky, J., Torner, H., Toth, P., and Schneider, F.: Reproduction in the Hungarian Mangalica pig, Pig News and Information, 26, 23N-28N, 2005.

Brüssow, K.-P., Torner, H., Rátky, J., Manabe, N., and Tuchscherer, A.: Experimental evidence for the influence of cumulus-oocytecomplexes on sperm release from the porcine oviductal sperm reservoir, J. Reprod. Dev., 52, 249-257, 2006.

Brüssow, K.-P., Schneider, F., Tuchscherer, A., Rátky, J., Kraeling, R. R., and Kanitz, W.: Luteinizing hormone release after administration of the GnRH agonist Fertilan (goserelin) for synchronization of ovulation in pigs, J. Anim. Sci., 85, 129-137, 2007.

Brüssow, K.-P., Schneider, F., Tuchscherer, A., Egerszegi, I., and Rátky, J.: Comparison of LH, leptin and progesterone levels in systemic circulation (Vena jugularis) and near the ovarian circulation (Vena. cava caudalis) during the oestrous cycle in Mangalica and Landrace gilts, J. Reprod. Dev., 54, 431-438, 2008.

Brüssow, K.-P., Torner, H., and Rátky, J.: Sperm migration in pigs after deep intrauterine and intraperitoneal insemination, J. Reprod. Dev., 57, 342-345, 2011.

Brüssow, K.-P., Vernunft, A., Kempisty, B., and Rátky, J.: Single fixed-time laparoscopic intrauterine insemination as a tool to obtain low-diversity porcine embryos, Vet. Med.-Czech, 58, 412416, 2013.
Egerszegi, I., Torner, H., Rátky, J., and Brüssow, K.-P.: Follicular development and preovulatory oocyte maturation in Hungarian Mangalica and Landrace gilts, Arch. Tierzucht, 44, 413-419, 2001.

Egerszegi, I., Rátky, J., Solti, L., and Brüssow, K.-P.: Mangalica an indigenous breed from Hungary (Review), Arch. Tierzucht, 46, 245-256, 2003a.

Egerszegi, I., Schneider, F., Rátky, J., Soós, F., Solti, L., Manabe, N., and Brüssow, K.-P.: Comparison of luteinizing hormone and steroid hormone secretion during the peri- and postovulatory periods in Mangalica and Landrace gilts, J. Reprod. Dev., 49, 291 296, 2003b.

Egerszegi, I., Hazeleger, W., Rátky, J., Sarlós, P., Kemp, B., Bouwman, E., Solti, L., and Brüssow, K.-P.: Superovulatory ovarian response in Mangalica gilts is not influenced by feeding level. Reprod. Dom. Anim. 42, 441-444, 2007.

Egerszegi, I., Sarlós, P., Brüssow, K.-P., Casado, P. G., Jekkel, G., and Rátky, J.: Laparoscopic insemination of Mangalica gilts with low dose fresh and frozen/thawed semen - pilot study (in Hungarian) Animal Welfare Ethology and Housing Systems (AWTH), 5, 329-336, 2009a.

Egerszegi, I., Sarlós, P., Berger, B., and Rátky, J.: Cryopreservation of semen from native Hungarian Mangalica boars - a pilot study VIII, International Conference on Pig Reproduction 2009, Banff, Canada, 125, 2009b.

Egerszegi, I., Sarlós, P., Csík, J., Berger, B., Tóth, P., and Rátky, J.: Artificial insemination in Mangalica breeding - present situation and future prospects, Proceedings of 22nd Annual Meeting of EU-AI Vets, 16 September, Eger, Hungary, 78-82, 2010.

Rátky, J. and Brüssow, K.-P.: Successful embryo recovery from swine by minimal invasive technique, Acta Vet. Hung., 43, 371375, 1995.

Rátky, J., Brüssow, K.-P., and Hunter, M.: Endoscopic studies of ovarian follicle development during the oestrous cycle in Hungarian Large White gilts, Arch. Tierzucht, 38, 427-435, 1995.

Rátky, J., Brüssow, K.-P., Solti, L., Torner, H., and Sarlos, P.: Ovarian response, embryo recovery and results of embryo transfer in a Hungarian native breed, Theriogenology, 56, 969-978, 2001.

Rátky, J., Rath, D., and Brüssow, K.-P.: In vitro fertilisation of in vivo matured porcine oocytes obtained from prepuberal gilts at different time intervals after hCG injection, Acta Vet. Hung., 51, 95-101, 2003.

Rátky, J., Torner, H., Egerszegi, I., Schneider, F., Sarlós, P., Manabe, N., and Brüssow, K.-P.: Ovarian activity and oocyte development during follicular development in pigs at different reproductive phases estimated by the repeated endoscopic method, J. Reprod. Dev., 51, 109-115, 2005.

Rátky, J., Egerszegi, I., Toth, P., Keonuchan, S., Nagai, T., Kikuchi, K., Manabe, N., and Brüssow, K.-P.: Saving Genetic Resources of Native Pigs in Occidental and Oriental Countries - Practical Examples of the Characterization and Utilization of Native Pigs in Hungary and Laos, J. Reprod. Dev., 59, 437-441, 2013.

Sarlós, P., Egerszegi, I., Nagy, S., Fébel, H., and Rátky, J.: Reproductive function of Hungarian Mangalica boars: effect of seasons, Acta Vet. Hung., 59, 257-267, 2011.

Torner, H., Brüssow, K.-P., Alm, H., and Rátky, J.: Morphology of porcine cumulus-oocyte-complexes depending on stage of preovulatory maturation, Theriogenology, 50, 39-48, 1998. 
Torner, H., Brüssow, K.-P., Alm, H., Rátky, J., Pöhland, R., Tuchscherer, A., and Kanitz, W.: Mitochondrial aggregation patterns and activity in porcine oocytes and apoptosis in surrounding cumulus cells depend on the stage of preovulatory maturation, Theriogenology, 61, 1675-1689, 2004.
Zsolnai, A., Tóth, G., Molnár, J., Stéger, V., Marincs, F., Jánosi, A., Ujhelyi, G., Koppányné Szabó, E., Mohr, A., Anton, I., SzántóEgész, R., Sipos, R., Egerszegi, I., Dallmann, K., Tóth, P., Micsinai, A., Brüssow, K.-P., and Rátky, J.: Identification of nine SNPs distinguishing varieties of Mangalica breed and a SNP set for parentage testing in Mangalica, Arch. Tierzucht, 56, 200-207, 2013. 